\title{
Psychopathology, symptoms of attention-deficit/ hyperactivity disorder, and risk factors in juvenile offenders
}

\author{
Francesco Margari' \\ Francesco Craig ${ }^{2}$ \\ Lucia Margari² \\ Emilia Matera ${ }^{2}$ \\ Anna Linda Lamanna ${ }^{2}$ \\ Paola Alessandra Lecce ${ }^{2}$ \\ Donatella La Tegola ${ }^{3}$ \\ Felice Carabellese ${ }^{3}$ \\ 'Psychiatry Unit, ${ }^{2}$ Child \\ Neuropsychiatry Unit, Department \\ of Basic Medical Sciences, \\ Neurosciences and Sense Organs \\ of the Aldo Moro University of Bari, \\ ${ }^{3}$ Section of Criminology and Forensic \\ Psychiatry, Department of Internal \\ Medicine and Public Medicine, \\ University of Bari, Bari, Italy
}

Correspondence: Lucia Margari

Child Neuropsychiatry Unit, Department of Basic Medical Sciences, Neurosciences and Sense Organs of the Aldo Moro University of Bari, Hospital Polyclinic of Bari, Piazza Giulio Cesare I, Bari, Italy Email lucia.margari@uniba.it
This article was published in the following Dove Press journal:

Neuropsychiatric Disease and Treatment

10 February 2015

Number of times this article has been viewed

Background: The aim of this study was to assess the prevalence of potential environmental and psychopathological risk factors, with special focus on symptoms of attention-deficit/ hyperactivity disorder (ADHD), in a sample of adolescent offenders in relation to the type of crime committed.

Methods: The assessment included data collection and administration of clinical standardized scales such as the Youth Self-Report and Conners' Adolescent Self-Report Scale. A total of 135 juvenile offenders participated in the study. In relation to the type of crime committed, we identified three groups matched for age and sex (crimes against people, property crimes, and alcohol-drug-related crimes).

Results: Fifty-two percent of juvenile offenders reported educational achievement problems and $34 \%$ reported a family history of psychiatric disorders. We detected a statistically significant difference between the three groups with regard to $\operatorname{ADHD}(P=0.01)$ and conduct problems $(P=0.034)$. Juvenile offenders who had committed crimes against people showed more ADHD symptoms $(18 \%)$ and conduct problems $(20 \%)$ than adolescents who had committed property crimes and alcohol-drug-related crimes. Sixty percent of the juvenile offenders who had committed property crimes and 54\% of those who had committed alcohol-drug-related crimes showed problems in academic achievement.

Conclusion: These findings suggest the need to implement specific interventions for prevention and treatment of specific criminal behavior.

Keywords: juvenile offenders, attention-deficit/hyperactivity disorder, conduct problems, academic achievement problems, peer relationships, family problems

\section{Introduction}

The alarming rate of criminal involvement among adolescents and young adults is a major concern in the USA and in many other European countries. ${ }^{1,2}$ Moreover, it is not surprising that a majority of youth who have perpetrated violent crimes and are placed in detention have mental health difficulties. Although decades of scientific research aimed at understanding the phenomenon of juvenile offenders has resulted in the recognition of many environmental and individual risk factors, the relationship between adolescent delinquency and general psychopathology remains largely unexplored. One condition that is often neglected in forensic settings is attention-deficit/hyperactivity disorder (ADHD), which could be a precursor of later antisocial behavior.

\section{Juvenile offenders and general psychopathology}

Young offenders show high rates of psychosocial risk factors, such as impulsive temperament characteristics, emotional and behavior problems, low academic performance, 
substance or alcohol abuse, poor relationships with parents and peers, and mental health problems. ${ }^{3-6}$ Teplin et al showed that, excluding conduct disorder (common among detained youth), nearly $60 \%$ of males and over two thirds of females met diagnostic criteria and had diagnosis-specific impairment for one or more psychiatric disorders (affective disorder, anxiety, psychosis, ADHD, disruptive behavior disorders, and substance use disorders). ${ }^{7}$ In a review study, Vermeiren et al found varied psychiatric disorders in offender samples, which included conduct and oppositional disorders, depressive and anxiety disorders, post-traumatic stress disorder, and ADHD. ${ }^{8}$ Recently, Coker et al examined relationships between psychiatric disorders and self-reported crime involvement in a sample of youth representative of the US population. ${ }^{9}$ The authors detected that youth with lifetime psychiatric disorders, compared with youth with no disorders, had significantly greater odds of crime, including violent crime, while for violent crime resulting in arrest, conduct disorder, alcohol use disorders, and drug use disorders had the greatest odds, with similar findings for violent crime with no arrest. These findings highlight the importance of developing mental health services for juvenile offenders and the necessity of adequate diagnostic and therapeutic interventions in these adolescents.

\section{Juvenile offenders and ADHD}

A considerable amount of evidence demonstrates that children diagnosed with ADHD are at high risk of criminality; however, the role of ADHD in the prediction of criminality remains unclear in both clinical and population-based studies. ${ }^{10,11}$ Bulten et al revealed that $38 \%$ of adult offenders retrospectively received the diagnosis of ADHD during their childhood. ${ }^{12}$ On the other hand, a significantly elevated risk for oppositional defiant disorder, conduct disorder, and many longterm adverse outcomes, including criminality, are frequently found in children with ADHD. ${ }^{13-15}$ Barkley detected that children with ADHD were more likely to engage in a variety of antisocial activities in comparison with a control group, and that the frequency of such activities was largely predicted by the severity of ADHD in childhood and adolescence. ${ }^{10}$ Prospective studies reported that children having high levels of ADHD often show disruptive behavior patterns, especially during adolescence, suggesting that hyperactivity could be a predictor of antisocial behavior. ${ }^{14,15}$ In particular, Molina et al reported that, at age 13-18 years, approximately 25\%-30\% of ADHD youths were in the spectrum of clinically serious antisocial behavior, $26.8 \%$ had been arrested at least once, and $30 \%$ had engaged in moderately serious to serious delinquent behavior. ${ }^{16}$ On the contrary, Pingault et al showed that although the contribution of childhood hyperactivity to criminality may be detected in large samples using multi-informant longitudinal designs, ADHD is not a strong predictor of later criminality. ${ }^{17}$ An important gap in the current literature regarding the risk of antisocial and aggressive behavior in children and adolescents is that to date theoretical frameworks of early risk factors for violence and aggression have not effectively integrated social and biological factors. Further, mental health risk factors have been largely ignored in these frameworks. One exception is the model proposed by Moffitt, which distinguishes two main categories in the description of severity and continuity of antisocial behavior in the pediatric age group, ie, a "life-course persistent" (LCP) group, characterized by persistent antisocial behavior that starts early in life, and an "adolescent-limited" group, in which the antisocial behavior starts during adolescence and remains restricted to this period. ${ }^{18}$ In particular, ADHD could play a crucial role in the development of LCP delinquency, which may also help to explain the genetic predisposition for LCP offending. In the same vein, Loeber et al suggested that in children in whom the onset of aggression occurs in the preschool period, antisocial behavior/criminal behavior is considered to be especially persistent when the child fulfils the diagnostic criteria for an ADHD diagnosis. ${ }^{19}$ Nevertheless, even today in the criminal justice system, ADHD is a neglected vulnerability, which can leave a suspect disadvantaged during court proceedings and prevention or treatment of criminal behavior. ${ }^{20}$ For these reasons, the aim of this study was to evaluate potential environmental and psychopathological risk factors, focusing especially on ADHD symptoms, in a sample of juvenile offenders in relation to the type of crime committed. We hypothesized that symptoms of ADHD could represent a prognostic factor for the development of specific criminal activity.

\section{Materials and methods Participants}

The study was conducted by the Child Neuropsychiatry Unit in collaboration with the Section of Criminology and Forensic Psychiatry at the University of Bari Aldo Moro. The sample involved adolescents of both sexes, with an age range of 14-18 years, adjudicated by the Juvenile Court of Puglia for committing a first crime where the Public Prosecutor's Office considered that there was sufficient evidence of responsibility in committing the crime. Exclusion criteria included any other serious medical condition and migrant adolescents who did not have a complete understanding of the Italian language. In addition, individuals with a previous 
psychiatric disorder were excluded from the study because the Italian justice system considers a suspect not punishable if he/she was suffering from a psychiatric disorder at the time of committing the offence. Consents of the legal authorities of the Juvenile Court were obtained. Written informed consent was obtained by adolescents and their parents after providing all the details of the study procedure.

\section{Assessment}

The assessment included collection of information regarding each subject enrolled in the study, obtained through a semistructured interview developed ad hoc and administration of clinical standardized scales, including the Youth Self-Report (YSR) for age 11-18 years ${ }^{21}$ and the Conners' Adolescent Self-Report Scale (CASS). ${ }^{22}$

\section{Semistructured interview}

A semistructured interview was developed in order to elicit a detailed account of each participant's experiences. This consisted of the following five main sections: criminal records, quality of family relationships, peer relationships, academic achievement, and antisocial behavior.

\section{Criminal records}

Criminal records involved three type of crimes: crimes against people, property crimes, and alcohol-drug-related crimes. The crimes against people group included adolescents who had been convicted of stalking, assault, physical injuries, sexual harassment, and bodily harm. The property crimes group included adolescents who had been convicted of theft from private property, architectural theft, damage to buildings or monuments, arson, graffiti, and other forms of antisocial behavior in proximity to heritage assets. The alcohol-drugrelated crimes group included adolescents who had been convicted of alcohol and/or drug abuse, drug trafficking, or possession of drugs.

\section{Quality of family relationships}

Quality of family relationships was classified as adequate or poor. For adequate quality of family relationships, we referred to the presence of appreciation for one another, good communication skills, a large amount of time spent together, and good coping ability. For poor quality of family relationships, we referred to the presence of at least one of the following problems: poor appreciation for one another, low communication skills, a small amount of time spent together, poor coping ability, conflicting relationships, and low levels of family support.

\section{Peer relationships}

Peer relationships were classified as adequate or poor. For adequate peer relationships, we referred to the presence of stable interpersonal relationships, assertiveness and altruistic behaviors, and belonging to group dynamics. For poor peer relationships, we referred to the presence of at least one of the following problems: no friends, peer rejection, and social withdrawal.

\section{Academic achievement}

Academic achievement was classified as regular or irregular. For regular academic achievement, we referred to number of years of education appropriate to the age of the subject or completion of compulsory education that in Italy is from 6 to 16 years of age. For irregular academic achievement, we referred to the presence of at least one of the following problems: discontinuity of schooling, low academic performance, and dropout from school.

\section{Antisocial behavior}

The previous antisocial behavior section included failure to conform to social norms. The antisocial behavior was classified as absent or present. For the presence of antisocial behavior, we referred to the presence of at least one of the following problems: domestic violence, repeated physical fights or assaults, alcohol and substance abuse, reckless disregard for safety of self or others, and failure to comply with police officers.

\section{Youth Self-Report}

The YSR is a prominent and widely used measure for assessment of emotional and behavioral problems among youth aged 11-18 years. The 119 items on the YSR are rated as 0 (not true), 1 (somewhat or sometimes true), or 2 (very true or often true). The developers of the YSR intended it to be completed by youths with a mental age of 10 years and fifth-grade reading skills. Validity and reliability of the YSR broad band and Diagnostic and Statistical Manual of Mental Disorders (DSM-IV)-oriented scales have been documented, and extensive normative data are available for children aged 11-18 years. The YSR contains the following subscales: anxious/depressed, withdrawn/depressed, somatic complaints, social problems, thought problems, attention problems, rule-breaking behavior, and aggressive behavior. These subscales are grouped into two higher order factors, ie, internalizing and externalizing problems. The 2001 revision also added six DSM-oriented scales consistent with DSM diagnostic categories: affective problems, anxiety problems, somatic problems, ADHD, oppositional defiant 
problems, and conduct problems. The YSR are also scored on competence scales for activities and competence in social relationships.

\section{Conners' Adolescent Self-Report Scale}

The CASS is the adolescent form of the Conners' Rating Scales-Revised (CRS-R). The CRS-R was designed to address the need for a multimodal assessment of behavioral difficulties in children and adolescents and contains a parent form and teacher form, as well as an adolescent self-report form. The adolescent self-report form, ie, CASS, is appropriate for adolescents aged 12-17 years, although some studies have examined its utility with children younger than 12 years. The CASS is designed to provide a self-report evaluation of various symptoms associated with ADHD. The CASS contains the following subscales: family problems, conduct problems, anger control problems, emotional problems, cognitive problems, hyperactive-impulsive symptoms, DSM-IV symptoms, and an ADHD Index.

\section{Statistical analysis}

Descriptive statistics were used to summarize the variables studied and the characteristics of the juvenile offenders. The Kuder-Richardson Formula 20 was used to check the internal consistency and reliability of the semistructured interview with dichotomous choices. Values can range from 0.00 to 1.00. A value of at least 0.70 is desirable. We found a KuderRichardson 20 Index of 0.80 , indicating that the items show good internal consistency and reliability.

Raw scores obtained for each subscale of the YSR and CASS were transformed to $t$-scores to allow for consideration of how an individual's response compares with that of the population norms. In the statistical analysis, we detected the performance of mean values of the YSR and CASS. For the YSR, the borderline $(t$-score $>65)$ and clinical $(t$-score $>70)$ groups were put together. In line with the interpretive guidelines for CASS, participants with a $t$-score of 66 on a subscale represent individuals who score well above average and are categorized as symptomatic for that trait. The sample was divided in relation to the type of crime committed, and we identified three groups. In order to analyze the frequency of the psychopathology with a qualitative analysis, we reported the frequencies in terms of presence or absence in reference to the cut-off of each scale on the YSR and CASS respectively. Chi-square $\left(\chi^{2}\right)$ independence was used to examine the differences between the three groups. The analysis of variance test was used to evaluate the mean differences on the YSR and CASS scales between the three groups. In addition, Bonferroni correction was used to conduct the post hoc analysis. Variables showing a $P$-value $<0.05$ in the univariate analyses were included as associated factors in the multiple linear regression analysis. The multiple regression analysis was used to analyze the relationship between the statistically significant dependent variable (ADHD and conduct problems) and a combination of dichotomous predictor variables, such as quality of family relationships, peer relationships, academic achievement, and antisocial behavior.

A $P$-value of $<0.05$ was considered to be statistically significant for all the tests. For statistical processing, we used Statistical Package for the Social Sciences version 20 software (IBM Corporation, Armonk, NY, USA).

\section{Results}

A total of 135 juvenile offenders with a mean age of $16.28 \pm 0.8$ years participated in the study. A crime against people was committed by $37 \%$ of the participants, property crimes by $37 \%$, and alcohol-drug-related crimes by $26 \%$. The features of the study sample are summarized in Table 1.

The YSR results showed that internalizing problems were present in $23 \%$ of the juvenile offenders, manifesting

Table I Sociodemographic and criminal features of juvenile offenders

\begin{tabular}{ll}
\hline $\mathrm{n}$ & 135 \\
Sex & \\
$\quad$ Male & $89 \%$ \\
$\quad$ Female & $11 \%$ \\
School & \\
$\quad$ Junior & $63 \%$ \\
$\quad$ High & $36 \%$ \\
Family composition & \\
$\quad$ Nuclear & $90 \%$ \\
$\quad$ Single-parent & $10 \%$ \\
Family relationships & \\
$\quad$ Poor & $15 \%$ \\
$\quad$ Good & $85 \%$ \\
Psychiatric family history & $34 \%$ \\
Type of crime* & \\
$\quad$ Against people & $37 \%$ \\
$\quad$ Property crimes & $37 \%$ \\
$\quad$ Alcohol-drug-related & $26 \%$ \\
Educational achievement & \\
$\quad$ Regular & \\
$\quad$ Irregular & $48 \%$ \\
Peer relationships & $52 \%$ \\
Poor & \\
Good & $28 \%$ \\
Antisocial behavior & $72 \%$ \\
\hline Notes: ${ }^{*}$ Age $F=485, P=0.617 ;$ sex $F=957, P=0.387$. & $34 \%$ \\
\hline
\end{tabular}

Notes: *Age $F=485, P=0.617$; sex $F=957, P=0.387$. 
mainly as anxious/depressed (12\%) and withdrawn/depressed (13\%) problems. Thirty-one percent of the participants showed externalizing problems; in particular we found higher percentages in the presence of ADHD (10\%), oppositional defiant problems (19\%), conduct problems (11\%), and rulebreaking behavior (13\%).

The CASS results showed that $4 \%$ of the juvenile offenders exceeded the cut-off on the hyperactive-impulsive and DSM-IV symptoms scale, while 5\% exceeded the cut-off on the ADHD Index scale. All YSR and CASS scores for the juvenile offenders are reported in Table 2.

In relation to the type of crime committed, we identified three groups that showed no statistically significant differences in age $(P=0.617)$ or sex $(P=0.387)$. Comparing these three groups, we detected a statistically significant difference in problems of academic achievement $(P=0.03)$ and peer relationships $(P=0.04)$. In particular, adolescents

Table 2 YSR and CASS scores for juvenile offenders

\begin{tabular}{|c|c|c|}
\hline & $\begin{array}{l}\text { Percent above } \\
\text { cutoff }\end{array}$ & Mean \pm SD \\
\hline \multicolumn{3}{|l|}{$\overline{\text { YSR }}$} \\
\hline Activities & 41 & $35 \pm 8.2$ \\
\hline Social relationships & 11 & $4 I \pm 7.2$ \\
\hline Anxious/depressed & 12 & $55 \pm 7.9$ \\
\hline Withdrawn/depressed & 13 & $54 \pm 8.7$ \\
\hline Somatic complaints & 6 & $53 \pm 7.3$ \\
\hline Social problems & 5 & $52 \pm 7.1$ \\
\hline Thought problems & 2 & $52 \pm 6.3$ \\
\hline Attention problems & 13 & $54 \pm 8.9$ \\
\hline Rule-breaking behavior & 13 & $55 \pm 8.5$ \\
\hline Aggressive behavior & 12 & $56 \pm 9.4$ \\
\hline Internalizing problems & 23 & $51 \pm 11.1$ \\
\hline Externalizing problems & 31 & $52 \pm 12.1$ \\
\hline Total problems & 25 & $50 \pm 11.5$ \\
\hline Affective problems & 9 & $54 \pm 7.3$ \\
\hline Anxiety problems & 5 & $54 \pm 7.2$ \\
\hline Somatic problems & 10 & $54 \pm 7.7$ \\
\hline ADHD & 10 & $53 \pm 7.7$ \\
\hline Oppositional defiant problems & 19 & $55 \pm 8.5$ \\
\hline Conduct problems & 11 & $54 \pm 8.5$ \\
\hline \multicolumn{3}{|l|}{ CASS } \\
\hline Family problems & 2 & $45 \pm 6.8$ \\
\hline Conduct problems & 4 & $48 \pm 8.8$ \\
\hline Anger control problems & 5 & $45 \pm 8.3$ \\
\hline Emotional problems & 2 & $45 \pm 6.8$ \\
\hline Cognitive problems & 4 & $45 \pm 9.3$ \\
\hline Hyperactive-impulsive & 4 & $44 \pm 8.8$ \\
\hline DSM-IV symptoms & 4 & $45 \pm 8.9$ \\
\hline ADHD Index & 5 & $45 \pm 9.5$ \\
\hline
\end{tabular}

Abbreviations: YSR, Youth Self-Report; CASS, Conners' Adolescent Self-Report Scale; SD, standard deviation; ADHD, attention-deficit/hyperactivity disorder; DSM, Diagnostic and Statistical Manual of Mental Disorders. who had committed a crime against people reported more peer relationship problems (34\%) than the other two groups, while adolescents who had committed property crimes $(60 \%)$ and alcohol-drug-related crimes (54\%) showed a greater irregularity in their school career compared with the crime against people group. Analyzing the results obtained from the YSR, no statistically significant differences were found between the type of crime groups with regard to internalizing and externalizing problems, while statistically significant differences were found between the three groups with regard to $\operatorname{ADHD}(P=0.02)$ and conduct problems $(P=0.03)$. Post hoc analysis showed that adolescents who had committed crimes against people had more ADHD symptoms and conduct problems when compared with adolescents who have committed property crimes and alcohol-drug-related crimes. In addition, the CASS results showed a higher percentage of hyperactive-impulsive symptoms, DSM-IV Symptoms and ADHD Index in adolescents who had committed crimes against people compared with the other groups, but no statistically significant differences were found. The differences between the three groups are summarized in Table 3 .

Multiple regression was used to evaluate the impact of predictor variables such as academic achievement, family relationships, antisocial behavior, and peer relationships on the ADHD and conduct problem scores (Table 4). In the crime against people group, we found that problems in academic achievement $(P=0.003)$ and peer relationships ( $P=0.002)$ were significant predictors of ADHD score. In addition, the presence of problems in academic achievement were significant predictors of conduct problem score $(P=0.016)$ in the same group. In the crime against property group, we detected that problems in family relationships $(P=0.001 ; P=0.001)$ and peer relationships $(P=0.003$; $P=0.004)$ were significant predictors of ADHD score and conduct problems, respectively. In the alcohol-drug-related crimes group, the presence of antisocial behavior was a significant predictor of conduct problems $(P=0.009)$.

\section{Discussion}

Juvenile offenders are a very complex population, where it becomes important to have a global vision of the adolescent, including family and individual risk factors. Several family risk factors for delinquent behavior have been reported, including weak bonding with parents, inadequate parenting, abandonment by parents, family stress, family antisocial behavior, and family history of psychiatric disorders..$^{23-25}$ Other risk factors related to delinquent behavior include difficulty in social relationships, little interest in school, and low 
Table 3 Features and clinical outcome for offenders divided by type of crime

\begin{tabular}{|c|c|c|c|c|c|c|c|c|}
\hline & \multicolumn{2}{|c|}{ Against people } & \multicolumn{2}{|c|}{ Property } & \multicolumn{2}{|c|}{ Alcohol-drug-related } & \multirow[t]{2}{*}{$\mathbf{F}$} & \multirow[t]{2}{*}{$P$-value } \\
\hline & $\%$ & Mean \pm SD & $\%$ & Mean \pm SD & $\%$ & Mean \pm SD & & \\
\hline Sex (male) & 84 & - & 92 & - & 91 & - & 0.96 & 0.38 \\
\hline Academic achievement & 36 & - & 60 & - & 54 & - & 3.53 & $0.03^{*}$ \\
\hline Family relationships & 10 & - & 22 & - & 5 & - & 2.78 & 0.24 \\
\hline Antisocial behavior & 36 & - & 28 & - & 37 & - & 1.14 & 0.43 \\
\hline Peer relationships & 34 & - & 30 & - & 11 & - & 2.97 & $0.04 *$ \\
\hline \multicolumn{9}{|l|}{ YSR } \\
\hline Activities & 48 & $34.54 \pm 9.274$ & 44 & $34.68 \pm 8.17$ & 28 & $36.26 \pm 6.73$ & 0.52 & 0.60 \\
\hline Social relationships & 14 & $40.26 \pm 7.703$ & 6 & $42.02 \pm 5.71$ & 14 & $42.83 \pm 8.25$ & 1.46 & 0.24 \\
\hline Anxious/depressed & 10 & $56.24 \pm 6.912$ & 14 & $54.54 \pm 9.9$ & 11 & $55.5 \mathrm{I} \pm 6.12$ & 0.57 & 0.68 \\
\hline Withdrawn/depressed & 18 & $54.90 \pm 7.043$ & 8 & $53.34 \pm 9.72$ & 11 & $55.7 I \pm 7.63$ & 0.93 & 0.40 \\
\hline Somatic complaints & 6 & $53.88 \pm 5.363$ & 6 & $53.50 \pm 9.9$ & 5 & $53.77 \pm 5.5 \mid$ & 0.03 & 0.97 \\
\hline Social problems & 8 & $53.04 \pm 6.673$ & 4 & $51.98 \pm 9.0$ & 3 & $52.63 \pm 4.04$ & 0.03 & 0.97 \\
\hline Thought problems & 6 & $52.64 \pm 4.388$ & 8 & $51.60 \pm 8.4$ & 5 & $53.09 \pm 5.38$ & 0.28 & 0.76 \\
\hline Attention problems & 16 & $55.72 \pm 8.602$ & 18 & $54.50 \pm 11.32$ & 3 & $53.49 \pm 4.23$ & 0.66 & 0.52 \\
\hline Rule-breaking behavior & 16 & $56.10 \pm 6.947$ & 8 & $54.36 \pm 10.68$ & 14 & $56.89 \pm 7.12$ & 1.00 & 0.37 \\
\hline Aggressive behavior & 22 & $57.38 \pm 8.88$ & 14 & $54.74 \pm I I .43$ & 14 & $55.94 \pm 6.6 \mathrm{I}$ & 0.98 & 0.38 \\
\hline Internalizing problems & 22 & $52.08 \pm 10.05$ & 20 & $51.02 \pm 12.28$ & 28 & $50.40 \pm 11.18$ & 0.25 & 0.78 \\
\hline Externalizing problems & 32 & $53.10 \pm 11.9$ & 26 & $51.58 \pm 12.83$ & 37 & $52.91 \pm 11.66$ & 0.22 & 0.80 \\
\hline Total problems & 26 & $51.86 \pm 10.9$ & 24 & $50.22 \pm 11.98$ & 25 & $50.31 \pm 11.77$ & 0.30 & 0.74 \\
\hline Affective problems & 8 & $54.34 \pm 5.7$ & 8 & $53.42 \pm 9.51$ & 11 & $54.89 \pm 6.0$ & 0.43 & 0.65 \\
\hline Anxiety problems & 6 & $55.24 \pm 5.9$ & 6 & $53.08 \pm 9.24$ & 2 & $54.54 \pm 5.59$ & 1.14 & 0.32 \\
\hline Somatic problems & 8 & $54.70 \pm 6.2$ & 12 & $53.74 \pm 10$ & 8 & $53.74 \pm 5.79$ & 0.24 & 0.79 \\
\hline ADHD & 18 & $55.80 \pm 7.38$ & 8 & $53.00 \pm 9.42$ & 0 & $54.06 \pm 4.67$ & 2.91 & $0.02^{*, a}$ \\
\hline Oppositional defiant problems & 22 & $56.88 \pm 7.7$ & 14 & $54.58 \pm 10.1$ & 22 & $56.43 \pm 6.96$ & 1.00 & 0.37 \\
\hline Conduct problems & 20 & $55.88 \pm 8.2$ & 4 & $53.08 \pm 10.35$ & 8 & $54.17 \pm 5.13$ & 3.05 & $0.03^{*, a}$ \\
\hline \multicolumn{9}{|l|}{ CASS } \\
\hline Family problems & 4 & $47.68 \pm 8.23$ & 2 & $45.32 \pm 5.82$ & 0 & $44.31 \pm 5.39$ & 0.01 & 0.99 \\
\hline Conduct problems & 4 & $48.60 \pm 9.27$ & 0 & $48.80 \pm 7.86$ & 0 & $48.86 \pm 6.8$ & 2.91 & 0.06 \\
\hline Anger control problems & 4 & $45.34 \pm 9.3$ & 4 & $45.58 \pm 7.71$ & 3 & $45.34 \pm 7.88$ & 0.01 & 0.99 \\
\hline Emotional problems & 4 & $46.10 \pm 7.91$ & 0 & $45.96 \pm 7.4 I$ & 0 & $45.09 \pm 5.61$ & 0.23 & 0.80 \\
\hline Cognitive problems & 6 & $46.48 \pm|0.3|$ & 4 & $45.14 \pm 9.67$ & 3 & $43.97 \pm 7$ & 0.76 & 0.47 \\
\hline Hyperactive-impulsive & 6 & $46.24 \pm 10.2$ & 2 & $44.04 \pm 7.95$ & 9 & $42.60 \pm 7.65$ & 1.86 & 0.16 \\
\hline DSM-IV symptoms & 4 & $45.28 \pm 11.01$ & 2 & $43.70 \pm 8.50$ & 0 & $45.7 \mathrm{I} \pm 7.9$ & 0.72 & 0.49 \\
\hline ADHD Index & 10 & $47.38 \pm 10.8$ & 4 & $45.90 \pm 9.97$ & 0 & $43.29 \pm 5.92$ & 1.94 & 0.15 \\
\hline
\end{tabular}

Notes: $* P<0.05$; aBonferroni correction, against people $>$ property; against people $>$ alcohol-drug-related.

Abbreviations: YSR, Youth Self-Report; CASS, Conners' Adolescent Self-Report Scale; SD, standard deviation; ADHD, attention-deficit/hyperactivity disorder; DSM, Diagnostic and Statistical Manual of Mental Disorders.

Table 4 Risk factors predicting increased ADHD and conduct problem scores in juvenile offenders

\begin{tabular}{|c|c|c|c|c|c|c|c|c|c|c|}
\hline & & \multicolumn{3}{|c|}{ Against people } & \multicolumn{3}{|c|}{ Property } & \multicolumn{3}{|c|}{ Alcohol-drug-related } \\
\hline & & b & $t$ & $P$-value & b & $t$ & $P$-value & b & $t$ & $P$-value \\
\hline \multirow[t]{4}{*}{ ADHD } & Family relationships & -4.62 & -1.83 & 0.074 & $13.5 \mid$ & 4.22 & $0.001 *$ & -0.39 & -0.11 & 0.91 \\
\hline & Academic achievement & 5.88 & 3.14 & $0.003^{*}$ & -0.16 & -0.65 & 0.94 & -1.79 & -1.02 & 0.31 \\
\hline & Antisocial behavior & 0.14 & 0.078 & 0.938 & 4.04 & 1.47 & 0.14 & 2.41 & 1.36 & 0.18 \\
\hline & Peer relationships & 6.46 & 3.22 & $0.002 *$ & 11.5 & 3.18 & $0.003 *$ & 3.55 & 1.38 & 0.17 \\
\hline \multirow[t]{4}{*}{ Conduct } & Family relationships & -5.47 & -1.45 & 0.085 & 12.33 & 3.56 & $0.001 *$ & 0.69 & 0.22 & 0.82 \\
\hline & Academic achievement & 5.77 & 2.5 & $0.016^{*}$ & -1.27 & -0.46 & 0.64 & -1.66 & -1.1 & 0.28 \\
\hline & Antisocial behavior & $-2.8 \mathrm{I}$ & -1.19 & 0.23 & -0.81 & -0.27 & 0.78 & 4.22 & 3.01 & $0.009 *$ \\
\hline & Peer relationships & 4.04 & 1.63 & 0.1 & -12.04 & -3.07 & $0.004 *$ & 10.54 & 0.86 & 8.42 \\
\hline
\end{tabular}

Notes: b, standardized coefficient; $* P<05$.

Abbreviation: ADHD, attention-deficit/hyperactivity disorder. 
academic performance. ${ }^{26}$ In our sample, we found that $52 \%$ had educational achievement problems while $34 \%$ had a family history of psychiatric disorders. Unexpectedly, we found that $85 \%$ of juvenile offenders showed good family relationships, with only $15 \%$ showing poor family relationships. This finding differs from previous research reporting poor family relationships as a risk factor for future delinquency or crime. ${ }^{27}$ However, several studies detected a higher rate of delinquency in juveniles living in a single-parent family compared with juveniles living in a nuclear family, probably due to weaker parental control and supervision. ${ }^{28,29}$ Thus, the discrepancy between our finding and the data in the literature could be attributed to the fact that the $90 \%$ of our participants lived in a nuclear family. On the other hand, in the present study we also found that $72 \%$ of the participants reported good peer relationships, with only $28 \%$ reporting poor peer relationships. This finding could be linked to the previous data, considering the fact that good early family relationships promote good relationships within the family and with peers later in life, as suggested by attachment theory. ${ }^{30}$ In fact, a body of knowledge suggests that early family relationships as well as living in a nuclear family are important in the development of peer relationships. ${ }^{31,32}$

Recently, there has been an increasing amount of literature reporting internalizing and externalizing problems in juvenile offenders, such as anxiety, depression, substance abuse, conduct problems, ADHD, and oppositional defiant disorder; ${ }^{7,8,19}$ however studies that have evaluated the presence of externalizing and internalizing problems in juvenile offenders are lacking in Italy. In the present study, emotional and behavioral problems assessed by the YSR showed that juvenile offenders reported both externalizing (in 31\%) and internalizing problems (in 23\%). Internalizing problems were mainly represented by withdrawn/depressed (13\%), followed by anxious/depressed (12\%), somatic problems (10\%), and affective problems (9\%). Externalizing problems were mainly represented by oppositional defiant problems $(19 \%)$, followed by the rule-breaking behavior $(13 \%)$, conduct problems (11\%) and ADHD (10\%). The findings of the current study are consistent with other research which found that most adolescent offenders exhibit more externalizing behaviors (conduct disorder, ADHD, drug abuse) than typical internalizing mental health problems (depression, panic disorder, anxiety). ${ }^{33-35}$

In the present study, the CASS scores showed that $4 \%$ of adolescents exceeded the cut-off of the hyperactiveimpulsive and DSM-IV symptoms scale, while 5\% of adolescents exceeded the cut-off of the ADHD Index scale. These findings seem to be consistent with three epidemiological studies in Italy which reported the prevalence of ADHD to be about $4 \%$ during childhood and adolescence. ${ }^{36-38}$ However, the presence of ADHD symptoms may have been underestimated for several reasons. The hyperactivity symptoms decrease during adolescence, ${ }^{39}$ since our sample involves adolescents, the hyperactivity could be less detected than earlier assessments. In addition, since self-report questionnaires were used, these young offenders might not have reported behavioral problems, such as the presence of ADHD symptoms, for fear of providing negative information on himself/herself. Another aim of this study was to evaluate the environmental risk factors (family, social, and school difficulties) and psychopathology in relation to the type of crime committed. Mallett et al suggested that the broad array of offences classified under personal crimes can be caused or motivated by very different means. A youth who commits a sex offence or causes physical injury or bodily harm will undoubtedly differ in motivation from a youth who commits a robbery, theft on private property, or alcohol and drug abuse. ${ }^{40}$ For these reasons, we identified in our sample three groups in relation to the type of crime committed (crime against people, property crime, and alcohol-drug-related crimes). Previous longitudinal studies reported that ADHD could contribute more to drug-related and/or to non-violent crimes, but a recent study found that hyperactivity is not a strong predictor of later non-violent or mixed crime. ${ }^{16,41} \mathrm{In}$ our study, adolescents who committed crimes against people reported more peer relationship problems, ADHD symptoms, and conduct disorders compared with the other two groups. These problems could lead to reduced ability to evaluate social events objectively and commit subsequent aggressive behaviors.

The present findings seem to be consistent with those of Bagwell et al who found that ADHD children reported fewer close friendships and more peer rejection when compared with a non-ADHD group, suggesting that the long-term effects of ADHD on social functioning were more pronounced for children with persistent ADHD or conduct disorder in adolescence. ${ }^{42}$ Moreover, we found that academic achievement problems were more frequent in adolescents who committed property crimes $(60 \%)$ and alcohol-drugrelated crimes $(54 \%)$ compared with adolescents who committed crimes against people. This finding supports previous research describing a relationship between low academic performance and delinquency. ${ }^{43,44}$ There is evidence that the intellectual functioning of young offenders is in the low-average range and that they have significant deficits 
in reading, mathematics, and written and oral language compared with their non-offending peers, ${ }^{45}$ while higher academic performance was associated with desistance from offending. ${ }^{46}$ In addition, multiple regression was used to evaluate the impact of predictor variables, such as academic achievement, family relationships, antisocial behavior, and peer relationships, on the ADHD and conduct problem scores in the three groups. In the crimes against people group, academic achievement and peer relationship problems were associated with ADHD symptoms and problems in academic achievement was also associated with conduct problems. In the property crimes group, we found that the presence of family relationships and peer relationships difficulties were associated with ADHD and conduct problems, while antisocial behavior was a significant predictor of conduct problems in the alcohol-drug-related crimes group. This finding underscores the relevance of psychosocial risk factors in addition to possible genetic risk factors for increased ADHD symptoms in adolescents displaying antisocial behavior. In fact, an association with serotonergic gene expression has been described for several psychiatric disorders related to a general lack of impulse control and impulsive aggression, such as ADHD. ${ }^{47,48}$ In particular, Retz et al examined the relationship between serotonergic dysfunction and violent behavior, and demonstrated genetic regulation of violent behavior in a subgroup of male offenders with a history of childhood ADHD, suggesting a significant role of serotonin transporter functionality in violent behavior. ${ }^{47}$

Several limitations to this study need to be acknowledged. First, the reliance on a semistructured interview schedule for the measurement of qualitative variables raises concern about the validity of causal conclusions for a range of reasons, including systematic response distortions, different research methods, and the psychometric properties (reliability and validity) of questionnaire scales. Another limitation lies in the fact that the impact of ADHD on the continuation or amelioration of antisocial behavior in delinquent adolescents remains unclear. Several studies have reported that attention problems and impulsivity/hyperactivity constitute two genetically distinct groups, suggesting that differentiation of inattention from hyperactivity/impulsivity may be important, and also that different pathways towards delinquency may exist. ${ }^{49}$ Fletcher et al suggest that people with inattentive-type symptoms are more likely to commit crimes that might require some planning, such as selling drugs or burglary compared with individuals with no ADHD symptoms, whereas individuals with impulsive symptoms have the highest increase in criminal activity of all the ADHD types, and are more likely to be arrested and convicted of a crime. Individuals with the combined-type of ADHD symptoms had weaker associations with crime compared with individuals who have only inattentive or only hyperactive symptoms. Surprisingly, individuals with the combined-type of ADHD symptoms are not at a multiplicative risk of criminal activities. ${ }^{50}$

In conclusion, this is the first Italian study to examine the association between environmental and psychopathological risk factors, focusing especially on ADHD symptoms, and type of crime committed in a sample of adolescent offenders. The findings confirm the presence of family, social, and school difficulties in juvenile offenders. Moreover, ADHD and conduct disorders contribute to more crimes against people when compared with property and alcohol-drugrelated crimes, suggesting that ADHD could represent a risk factor to engage in specific crime, and this probability rises dramatically for ADHD children with conduct disorder. This finding suggests the need to implement interventions based on specific risk factors and psychopathologies for the treatment of criminal behavior. In addition, extended collaboration between the child, the adolescent psychiatrist, and the judicial system would be beneficial in preventing later criminality in children with ADHD. Further research is certainly needed to clarify this issue.

\section{Acknowledgments}

We thank the following personnel for their generous support: Manuela Tamma, Egle Alfarano, Andrea Lisi, Ignazio Grattagliano, Maria Elena Lafortezza, Foloriana Pinto, Francesca Perrini, Francesca Montemiglio, Rosanna Viale, Paola Cuna, Giuseppe Tucci, and Ermenegilda Scardaccione.

\section{Disclosure}

None of the authors has any conflict of interest to disclose. All authors have seen and approved the final version of the paper and accept responsibility for the data presented.

\section{References}

1. Junger-Tas J, Marshall I, Ribeud D. Delinquency in an International Perspective: The International Self-Reported Delinquency Study. New York, NY, USA: Kugler; 2003.

2. Junger-Tas J, Marshall I, Enzmann D, Killias M, Steketee M, Gruszczynska B. Juvenile Delinquency in Europe and Beyond: Results of the Second International Self-Report Delinquency Study. Berlin, Germany: Springer eBook; 2010.

3. Herrenkohl TI, Maguin E, Hill KG, Hawkins JD, Abbott RD, Catalano RF. Developmental risk factors for youth violence. J Adolesc Health. 2000;26(3):176-186. 
4. Nagin DS, Tremblay RE. Parental and early childhood predictors of persistent physical aggression in boys from kindergarten to high school. Arch Gen Psychiatry. 2001;58(4):389-394.

5. Abram KM, Teplin LA, McClelland GM, Dulcan MK. Comorbid psychiatric disorders in youth in juvenile detention. Arch Gen Psychiatry. 2003;60(11):1097-1108.

6. Carswell K, Maughan B, Davis H, Davenport F, Goddard N. The psychosocial needs of young offenders and adolescents from an inner city area. $J$ Adolesc. 2004;27(4):415-428.

7. Teplin LA, Abram KM, McClelland GM, Dulcan MK, Mericle AA. Psychiatric disorders in youth in juvenile detention. Arch Gen Psychiatry. 2002;59(12):1133-1143.

8. Vermeiren R. Psychopathology and delinquency in adolescents: a descriptive and developmental perspective. Clin Psychol Rev. 2003;23(2):277-318.

9. Coker KL, Smith PH, Westphal A, Zonana HV, McKee SA. Crime and psychiatric disorders among youth in the U.S. population: an analysis of the national comorbidity survey - adolescent supplement. J Am Acad Child Adolesc Psychiatry. 2014;53(8):888-898.

10. Barkley RA, Fischer M, Smallish L, Fletcher K. Young adult follow-up of hyperactive children: antisocial activities and drug use. $J$ Child Psychol Psychiatry. 2004;45(2):195-211.

11. Mannuzza S, Klein RG, Moulton JL, III. Lifetime criminality among boys with attention deficit hyperactivity disorder: a prospective follow-up study into adulthood using official arrest records. Psychiatry Res. 2008(3);160:237-246.

12. Bulten E, Nijman H, van der Staak C. Psychiatric disorders and personality characteristics of prisoners at regular prison wards. Int J Law Psychiatry. 2009;32(2):115-119.

13. Belcher JR. Attention deficit hyperactivity disorder in offenders and the need for early intervention. Int J Offender Ther Comp Criminol. 2012;58(1):27-40.

14. Babinski LM, Hartsough CS, Lambert NM. Childhood conduct problems, hyperactivity-impulsivity, and inattention as predictors of adult criminal activity. J Child Psychol Psychiatry. 1999;40(3):347-355.

15. Taylor E, Chadwick O, Heptinstall E, Danckaerts M. Hyperactivity and conduct problems as risk factors for adolescent development. J Am Acad Child Adolesc Psychiatry. 1996;35(9):1213-1226.

16. Molina BS, Hinshaw SP, Swanson JM, et al. The MTA at 8 years: prospective follow-up of children treated for combined-type ADHD in a multisite study. J Am Acad Child Adolesc Psychiatry. 2009;48(5): 484-500.

17. Pingault JB, Côté SM, Lacourse E, Galéra C, Vitaro F, Tremblay RE. Childhood hyperactivity, physical aggression and criminality: a 19-year prospective population-based study. PLoS One. 2013;8(5):e62594.

18. Moffitt TE, Caspi A. Adolescent-limited delinquency and life-course persistent offending. Psychol Rev. 2001;100(4):674-701.

19. Loeber R, Slot W, Stouthamer-Loeber M. A Cumulative Developmental Model of Risk and Promotive Factors. Hampshire, UK: Ashgate Publishing Ltd; 2008.

20. Gudjonsson GH, Young S. An overlooked vulnerability in a defendant: attention deficit hyperactivity disorder and a miscarriage of justice. Legal and Criminological Psychology. 2006;11(2):211-218.

21. Achenbach TM. Manual for the Young Adult Self-Report and Young Adult Behavior Checklist. Burlington, VT, USA: Department of Psychiatry, University of Vermont; 1997.

22. Conners CK. Conners'Rating Scales-Revised. North Tonawanda, NY, USA: Multi-Health Systems; 1997.

23. Hoeve M, Blokland A, Dubas JS, Loeber R, Gerris JR, van der Laan PH. Trajectories of delinquency and parenting styles. J Abnorm Child Psychol. 2008;36(2):223-235.

24. Sentse M, Veenstra R, Lindenberg S, Verhulst FC, Ormel J. Buffers and risks in temperament and family for early adolescent psychopathology: generic, conditional, or domain-specific effects? The trails study. Dev Psychol. 2009;45(2):419-430.
25. Perdue TR, Williamson C, Ventura LA, et al. Offenders who are mothers with and without experience in prostitution: differences in historical trauma, current stressors, and physical and mental health differences. Womens Health Issues. 2012;22(2):195-200.

26. Mulder E, Vermunt J, Brand E, Bullens R, van Marle H. Recidivism in subgroups of serious juvenile offenders: different profiles, different risks? Crim Behav Ment Health. 2012;22(2):122-135.

27. Petrosino A, Derzon J, Lavenberg J. The role of family in crime and delinquency: evidence from prior quantitative reviews. Southwest Journal of Criminal Justice. 2009;6(2):108-132.

28. Schroeder RD, Osgood AK, Oghia MJ. Family transitions and juvenile delinquency. Sociol Inq. 2010;80(4):579-604.

29. Demuth S, Brown S. Family structure, family processes, and adolescent delinquency: the significance of parental absence versus parental gender. Journal of Research in Crime and Delinquency. 2004; 41(1):58-81.

30. Ainsworth MD. Attachments beyond infancy. Am Psychol. 1989;44(4):709-716.

31. Thienneman M, Shaw RJ, Steiner H. Defense style and family environment. Child Psychiatry Hum Dev. 1998;28(3):189-198.

32. Pallini S, Baiocco R, Schneider BH, Madigan S, Atkinson L. Early child-parent attachment and peer relations: a meta-analysis of recent research. J Fam Psychol. 2014;28(1):118-123.

33. Rayner J, Kelly TP, Graham F. Mental health, personality and cognitive problems in persistent adolescent offenders require long-term solutions: a pilot study. Journal of Forensic Psychiatry and Psychology. 2005;16(2):248-262.

34. Imbach D, Aebi M, Metzke CW, Bessler C, Steinhausen HC. Internalizing and externalizing problems, depression, and self-esteem in non-detained male juvenile offenders. Child Adolesc Psychiatry Ment Health. 2013;27(1):7-14.

35. Vieno A, Nation M, Perkins DP, Pastore M, Santinello M. Social capital, safety concerns, parenting, and early adolescents' antisocial behavior. J Community Psychol. 2010;38(3):314-328.

36. Gallucci F, Bird HR, Berardi C, Gallai V, Pfanner P, Weinberg A. Symptoms of attention-deficit hyperactivity disorder in an Italian school sample: findings of a pilot study. $J$ Am Acad Child Adolesc Psychiatry. 1993;32(5):1051-1158.

37. Camerini GB, Coccia M, Caffo E. [Attention deficit-hyperactivity disorder: frequency analysis in a school population through questionnaires to teachers]. Psichiatria dell'Infanzia e dell'Adolescenza. 1996;63:587-594. Italian.

38. Mugnaini D, Masi G, Brovedani P, et al. Teacher reports of ADHD symptoms in Italian children at the end of first grade. Eur Psychiatry. 2006;21(6):419-426.

39. Fergusson DM, Horwood LJ, Ridder EM. Show me your child at seven: the consequences of conduct problems in childhood for psychosocial functioning in adulthood. J Child Psychol Psychiatry. 2005;46(8):837-849.

40. Mallett C, Stoddard-Dare P, Workman-Crenshaw L. Special education disabilities and juvenile delinquency: a unique challenge for school social work. School Social Work Journal. 2011;36(1):26-40.

41. Sourander A, Elonheimo H, Niemela S, et al. Childhood predictors of male criminality: a prospective population-based follow-up study from age 8 to late adolescence. $J$ Am Acad Child Adolesc Psychiatry. 2006;45(5):578-586.

42. Bagwell CL, Molina BS, Pelham WE, Hoza B. Attention-deficit hyperactivity disorder and problems in peer relations: predictions from childhood to adolescence. J Am Acad Child Adolesc Psychiatry. 2001;40(11):1285-1292.

43. Loeber R, Farrington DP. Young children who commit crime: epidemiology, developmental origins, risk factors, early interventions, and policy implications. Dev Psychopathol. 2000;12(4):737-762.

44. Reinke WM, Herman KC. A research agenda for school violence prevention. Am Psychol. 2002;57(10):796-797. 
45. Leone PE, Christle CA, Nelson CM, Skiba R, Frey A, Jolivette K. School Failure, Race, and Disability: Promoting Positive Outcomes, Decreasing Vulnerability for Involvement with the Juvenile Delinquency System. Baltimore, MD, USA: National Center on Education, Disability, and Juvenile Justice, University of Maryland; 2003.

46. Flannery RB Jr, Everly GS Jr, Eyler V. The Assaulted Staff Action Program (ASAP) and declines in assaults: a meta-analysis. Int J Emerg Ment Health. 2000;2(3):143-148.

47. Retz W, Thome J, Blocher D, Baader M, Rösler M. Association of attention deficit hyperactivity disorder-related psychopathology and personality traits with the serotonin transporter promoter region polymorphism. Neurosci Lett. 2002;319(3):133-136.
48. Seeger G, Schloss P, Schmidt MH. Marker gene polymorphisms in hyperkinetic disorder - predictors of clinical response to treatment with methylphenidate? Neurosci Lett. 2001;313(1-2):45-48.

49. Willcutt EG, Pennington BF, DeFries JC. Twin study of the etiology of comorbidity between reading disability and attention-deficit/ hyperactivity disorder. Am J Med Genet. 2000;96(3):293-301.

50. Fletcher J, Wolfe B. Long-term consequences of childhood ADHD on criminal activities. J Ment Health Policy Econ. 2009;12(3):119-138.

\section{Publish your work in this journal}

Neuropsychiatric Disease and Treatment is an international, peerreviewed journal of clinical therapeutics and pharmacology focusing on concise rapid reporting of clinical or pre-clinical studies on a range of neuropsychiatric and neurological disorders. This journal is indexed on PubMed Central, the 'PsycINFO' database and CAS, and is the official journal of The International Neuropsychiatric Association (INA). The manuscript management system is completely online and includes a very quick and fair peer-review system, which is all easy to use. Visit http://www.dovepress.com/testimonials.php to read real quotes from published authors.

Submit your manuscript here: http://www.dovepress.com/neuropsychiatric-disease-and-treatment-journal 